\title{
Characterization of Diesel Split Injections with Negative and Positive Dwells
}

\author{
- Far-Field and Near-Field Spray Behaviors - \\ Qing WU, Yu JIN*, Chang ZHAI, Keiya NISHIDA, Yoichi OGATA \\ Graduate School of Advanced Science and Engineering, Hiroshima University, Higashi- \\ hiroshima, Japan \\ *Corresponding author email: jin@hiroshima-u.ac.jp
}

\begin{abstract}
Negative dwell injection, whose injection rate curves of the two injections partially overlap, is studied along with traditional split injection which is called positive dwell injection with the objective of distinguishing. The injection pressure and ambient pressure are fixed as $60 \mathrm{MPa}$ and 1.5MPa. Diffused Background Illumination (DBI) is adopted to photograph the spray behaviors from far and near fields. Based on the far-field results, it is found the spray characteristic of the negative dwell injection is between the single injection and positive dwell injection. Compared with positive dwell injection, the second spray of negative dwell injection can reach the tip of the first spray more rapidly and mix more evenly with each other. Nearfield experiment results confirm the droplets formed near nozzle will hinder the spray penetration of the second injection. For the negative dwell injection, high speed spray of the second injection will suck the droplets left by the first injection, making the spray edge smoother. Violent collision between the first and second sprays for negative dwell injection makes the spray concentration more uniform than other injection strategies. Negative dwell injection can inject more fuel while obtain similar spray characteristics to positive dwell injection within the same time interval.
\end{abstract}

\section{Keywords}

Diesel Spray; Split Injection; Injection Dwell; Spray Tip Penetration; Spray Cone Angle; Excess Air Ratio

\section{Introduction}

The rapid development of industrialization is increasingly worsening the problems of energy shortage and global climate change [1,2]. Stringent regulations related to energy conservation and emission reduction are implemented by governments worldwide to suppress further deterioration of the above problems [3]. These regulations have exerted tremendous pressure on the industries utilizing diesel engines, such as power generation, transportation and many other engineering applications. In an internal combustion engine, the main processes that control the engine performance and emissions can be divided into two parts. The first one is the mixture formation and it is determined by the injection system, swirls and turbulence in the cylinder. The second one is the ignition delay and combustion rate after ignition. Mixture formation, as a primary process, can not only influence the subsequent combustion process, but also the overall performance of internal combustion engines [4].

Multiple-injection, occasionally being called 'split injection', has been widely researched and proven to be able to curb nitrogen oxides (NOx) emissions and enhance soot oxidation [5]. Torregrosa et.al [6] and Yang et.al [7] found that multiple-injection could reduce the soot and NOx emissions of diesel engines effectively, while not increased other pollutant emission. Cheng and Hong [8] investigated the influence of multiple-injection strategy and exhaust gas 
recirculation (EGR) rate on the soot formation and combustion process in a heavy-duty diesel engine through the Two-color method. They found that increasing the time interval between pilot injection and main injection could shorten the ignition delay of the main combustion and reduced the emission of NOx and soot emission. Influence of pilot injection timing and mass on the emission characteristics was experimentally studied in a diesel engine fuelled with nbutanol-diesel blends by Huang [9]. Experimental results indicated that the more the advanced pilot injection timing and butanol amount was, the less NOx and soot emission would be. Though multiple-injection can reduce NOx and soot emission to a certain extent, compared with single-injection, the injection amount for multiple-injection during the same duration is less and the whole atomization process will take more time, which will limit the operation load conditions [10].

Given multiple injection plays a significant role in reducing emissions and enhancing engine performance, a new kind of multiple-injection strategy is proposed in this paper. Combining the new multiple-injection strategy with the traditional ones is likely to achieve better evaporation and combustion process. The main target of this study is to state the difference between the newly proposed multiple-injection strategy and traditional strategies from both far-field and near-field clearly. Relevant conclusions can provide a reference for enriching the existing multiple injection strategies.

\section{Experimental Setup and Conditions}

The Diffused Background Illumination (DBI) is adopted to study the difference between the negative dwell injection strategy and traditional injection strategies from both macroscopic and microscopic fields. The diagram of the experimental setup is shown in Figure 1.



Figure 1. Schematic of Experimental Setup

An injector with ten holes produced by Denso company is placed obliquely on the top of a constant volume chamber with four quartz windows. Light from a LED lamp shines on the target spray through a convex lens, diffuser and quartz windows. A high-speed video (HSV) camera is put on another side to photograph the target spray. The target spray is parallel to the imaging plane. The lenses of $105 \mathrm{~mm}$ and $200 \mathrm{~mm}$ focal length are used for far-field and near-field shooting, respectively. The frame rate is set as $25000 \mathrm{fps}$ for far-field shooting and $100000 \mathrm{fps}$ for near-field shooting. The resolution is set as $960 \times 376(0.098 \mathrm{~mm} /$ pixel $)$ for far- 
field and $384 \times 200(0.0127 \mathrm{~mm} /$ pixel) for near-field. All experiments are conducted under room temperature.

The diagram of 'positive dwell injection' is shown in Figure 2(a), when the EOI signals of the two injections are not that close, there will be a certain distance between the injection rate curves. If the EOI signals are close enough to each other, as displayed in Figure 2(b), the injection rate curves will partially overlap, making them look like one injection rate curve. The value of $h 1$ is about half of $h$. Such injection strategy is called 'negative dwell injection' hereafter.

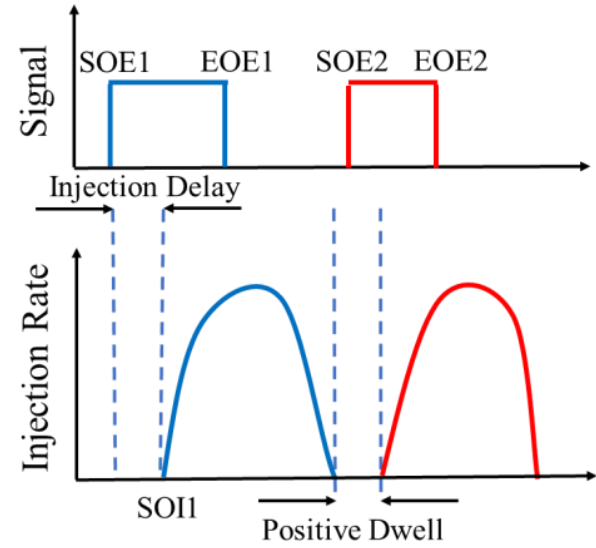

(a) Positive Dwell Injection Strategy

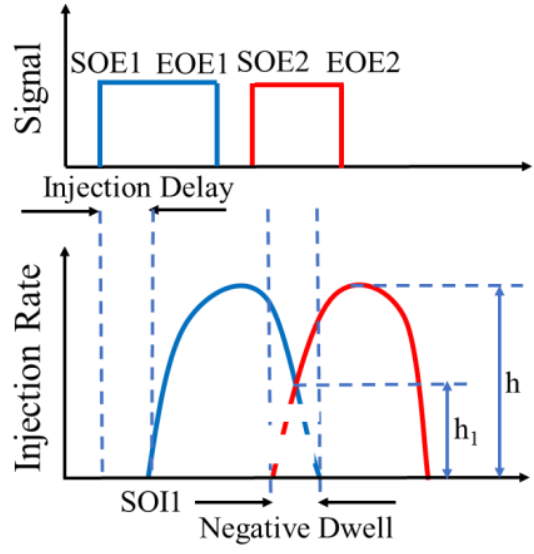

(b) Negative Dwell Injection Strategy

Figure 2. Definition of Injection Parameters

Experimental conditions are listed in Table 1 and corresponding injection rate curves are shown in Figure 3. 'P0.5-2.0ms' represents the positive dwell injection strategy with a positive dwell of $0.5 \mathrm{~ms}$ and an injection duration of $2.0 \mathrm{~ms}$. 'P0-2.0ms' denotes the positive dwell injection strategy with $0 \mathrm{~ms}$ positive dwell and $2 \mathrm{~ms}$ injection duration. The ' $1.0 \mathrm{~ms}$ ', ' $1.5 \mathrm{~ms}$ ' and '2.0ms' following ' $N$ ' represent the injection durations of negative dwell injection strategies. Single-injection of $2.0 \mathrm{~ms}$ injection duration is also included and represented as 'S-2.0ms'.

Table 1. Experimental Conditions

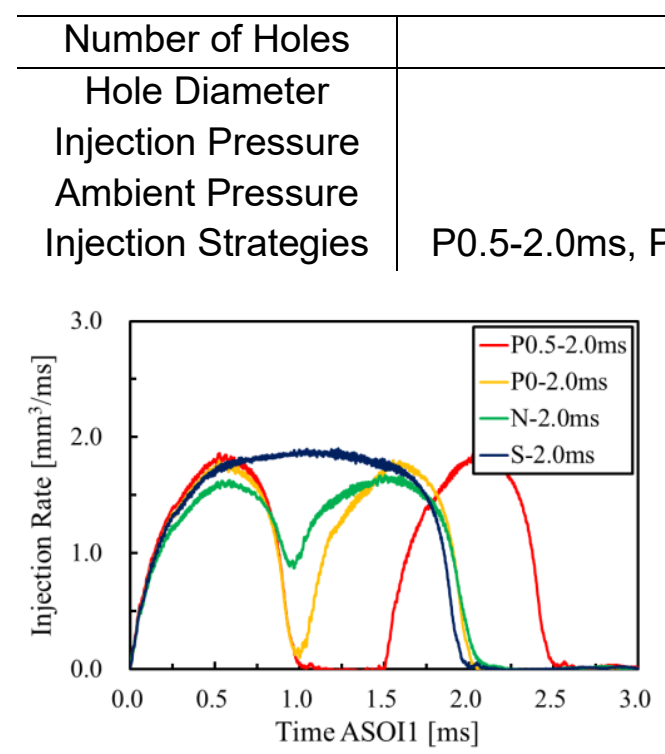

(a) Different Injection Strategies

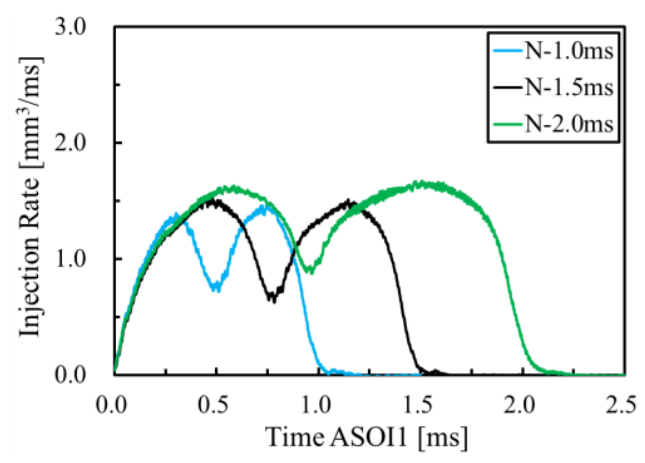

(b) Negative Dwell Injections with Different Injection Durations

Figure 3. Injection Rate Curves 


\section{Results and Discussion}

Analysis on the far-field spray behaviors

The pseudo-color images obtained via MATLAB are employed to analyze the concentration difference and they are shown in Figure 4. Red means high concentration and blue denotes low concentration. 'ASOI1' and 'ASOI2' represent the timings after the first and the second injection, separately. There is no distinct concentration difference for the target sprays of three injection strategies during the first injection. At $0.2 \mathrm{~ms} \mathrm{ASOI} 2$, the length of the red area for ' $\mathrm{N}$ $2.0 \mathrm{~ms}$ ' is significantly longer than that for ' $\mathrm{P} 0-2.0 \mathrm{~ms}$ ' and slightly longer than that for 'P0.5$2.0 \mathrm{~ms}$ '. At $1.2 \mathrm{~ms}$ ASOI2, the spray tip area for 'P0.5-2.0ms' has a higher concentration. The spray concentration distribution of ' $\mathrm{N}-2.0 \mathrm{~ms}$ ' is more uniform. Since the second injection for ' $\mathrm{N}-2.0 \mathrm{~ms}$ ' has higher kinetic energy than 'P0-2.0ms' and 'P0.5-2.0ms', the second injection can catch up with the tip of the first injection more quickly. At the same time, the collision effect between the droplets of the first and second injection makes the concentration distribution more uniform.

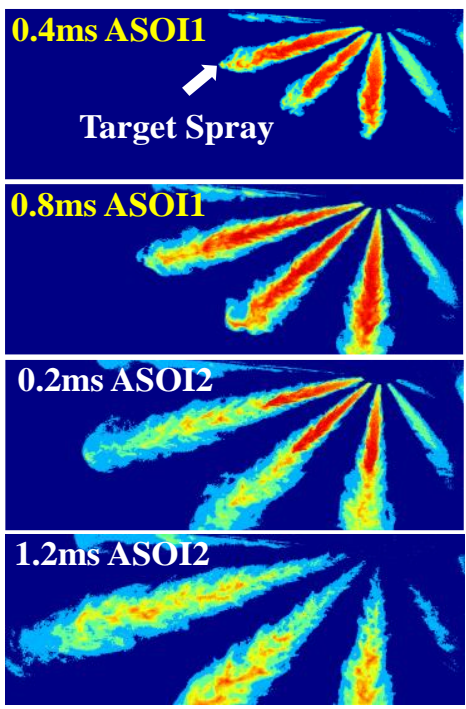

(a) $\mathrm{N}-2.0 \mathrm{~ms}$

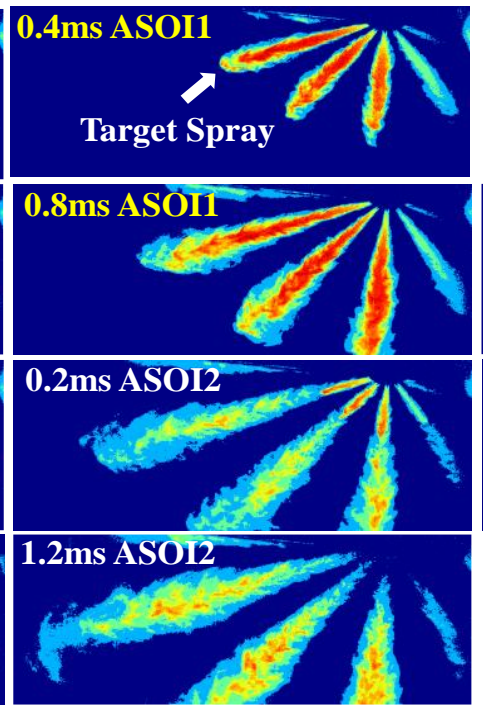

(b) $\mathrm{P} 0-2.0 \mathrm{~ms}$

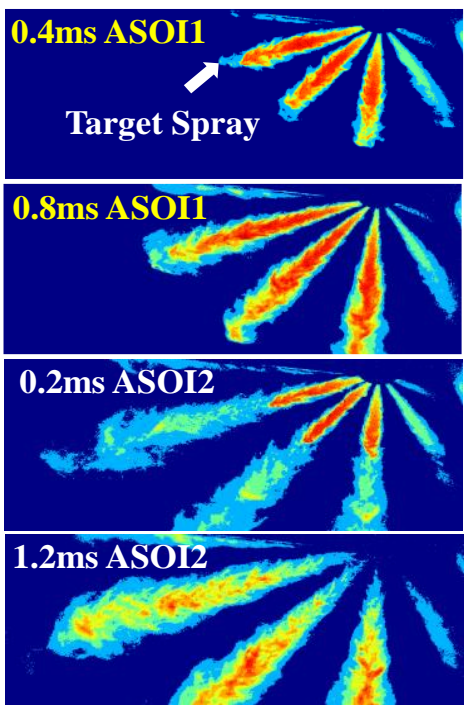

(c) P0.5-2.0ms

Figure 4. Concentration Difference for Different Injection Strategies

The image processing is done through the commercial software MATLAB and can be seen in Figure 5. As shown in Figure 5(d), 'O' represents the position of the nozzle, and the farthest distance between the nozzle and the spray tip area is defined as spray penetration ' $S$ '. At a distance of 100 times the nozzle diameter from the nozzle, the leftmost point of the spray ' $A$ ', along with the rightmost point ' $\mathrm{B}$ ' and ' $\mathrm{O}$ ', forms an angle 'AOB', which is defined as spray cone angle in this paper.

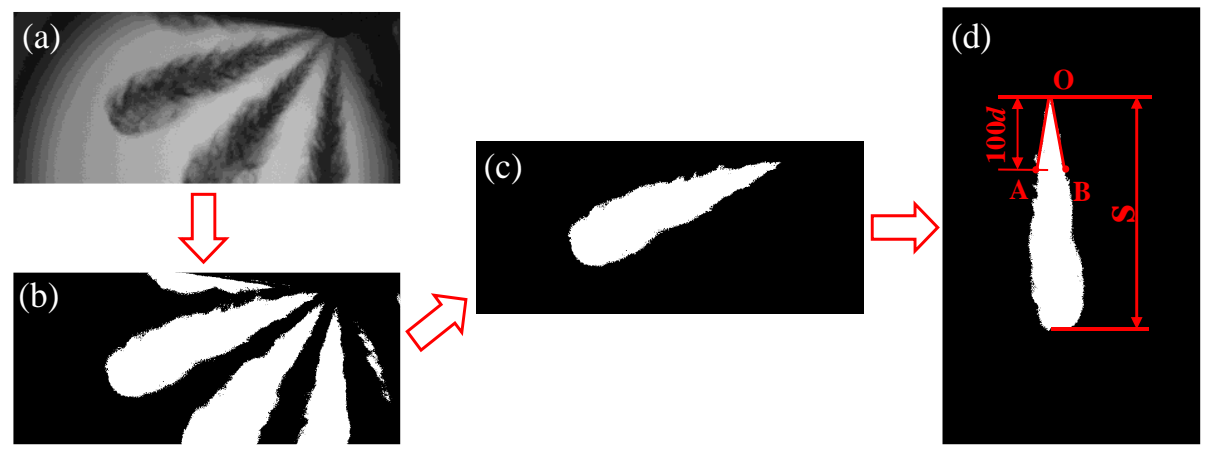

Figure 5. Schematic for Image Processing 
As shown in Figure 6(a), during the first injection period, the curves for different injection strategies basically overlap with each other. Before $2.0 \mathrm{~ms}$ ASOI1, the spray penetration for ' $\mathrm{N}-2.0 \mathrm{~ms}$ ' is close to that for 'P0.5-2.0ms' and the spray penetration for ' $\mathrm{P} 0-2.0 \mathrm{~ms}$ ' is the smallest. After 2.0ms ASOI1, spray penetration for ' $\mathrm{N}-2.0 \mathrm{~ms}$ ' continues to increase. But spray penetration for 'P0.5-2.0ms' starts to stabilize, approaching the spray penetration for 'P0$2.0 \mathrm{~ms}$ '. Such phenomenon is caused by the high kinetic energy in the second injection of ' $\mathrm{N}$ $2.0 \mathrm{~ms}$ ', which enables the second injection to catch up with the tip of the first injection and pushes the head further. The longer injection duration means more fuel amount, the more fuel amount means the greater resistance that needs to be overcome by the second spray. Therefore, the penetration difference between ' $\mathrm{N}-1.0 \mathrm{~ms}$ ' and ' $\mathrm{N}-1.5 \mathrm{~ms}$ ' displayed in Figure $6(b)$ is larger than that between ' $\mathrm{N}-1.5 \mathrm{~ms}$ ' and ' $\mathrm{N}-2.0 \mathrm{~ms}$ '.

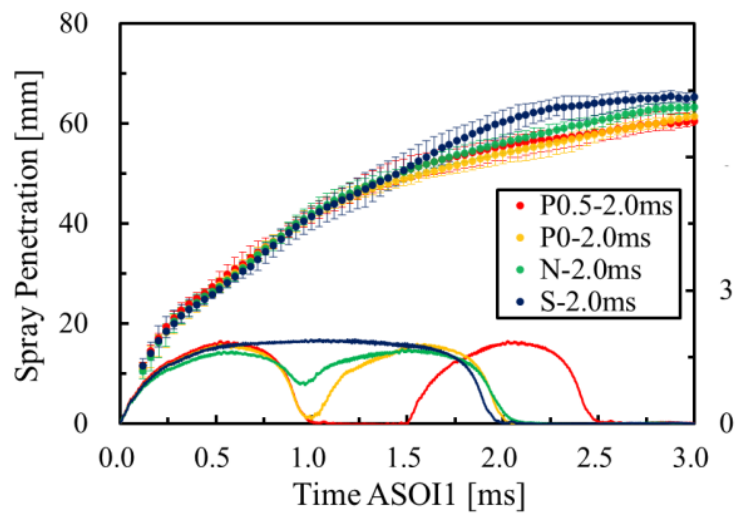

(a) Different Injection Strategies

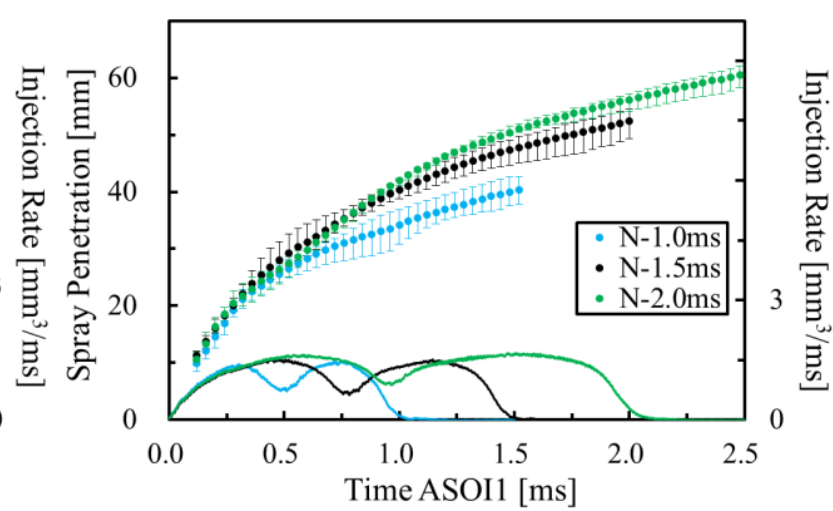

(b) Negative Dwell Injection Strategies with Different Injection Durations

Figure 6. Spray Penetration Variation with Time ASOI1

As shown in Figure 7(a), at the end of the first injection, spray cone angles for 'P0.5-2.0ms' and 'P0-2.0ms' have a sharp increase. But spray cone angle for ' $\mathrm{N}-2.0 \mathrm{~ms}$ ' is always stable. For 'P0.5-2.0ms' and 'P0-2.0ms', the second spray will push the first spray outside, increasing the spray cone angle. The growth rates of injection rates for ' $\mathrm{N}-1.0 \mathrm{~ms}$ ' and ' $\mathrm{N}-1.5 \mathrm{~ms}$ ' after the end of injection are larger than that for ' $\mathrm{N}-2.0 \mathrm{~ms}$ ', then more fuel is put aside, and spray cone angle increases slightly. Such behavior will aggravate the collision between the spray of the first and second injection, hereby promoting the atomization process. The curves in Figure 7 (b) all have similar trends, indicating injection duration does not affect spray cone angle.

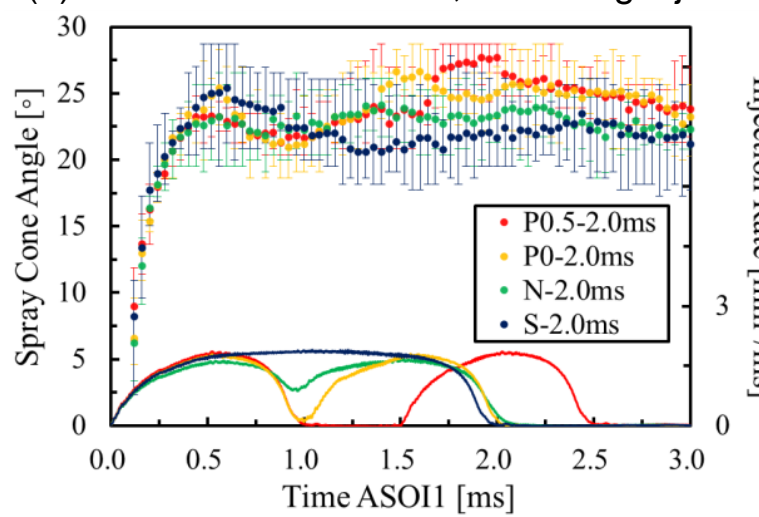

(a) Different Injection Strategies

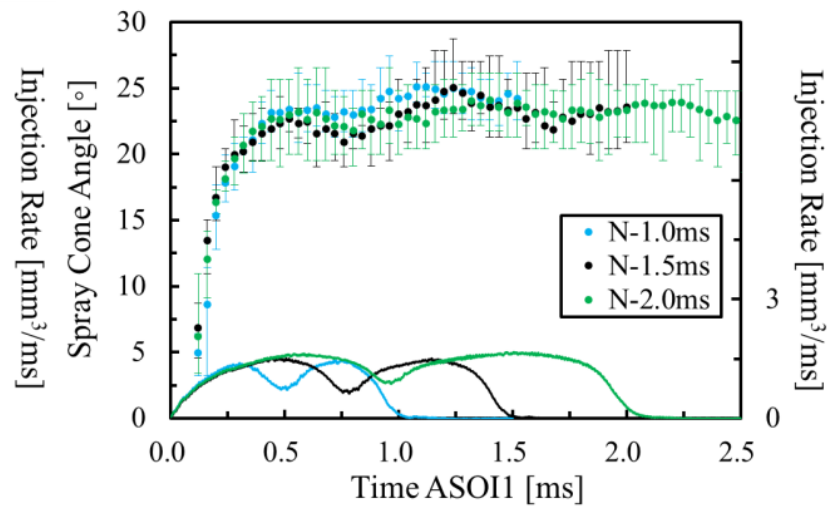

(b) Negative Dwell Injection Strategies with Different Injection Durations

Figure 7. Spray Cone Angle Variation with Time ASOI1 
Excess air ratio is defined as the ratio between the air amount calculated by multiplying the spray volume and gas density and the amount of stoichiometric air. In Figure 8(a), excess air ratios for 'P0.5-2.0ms', 'P0-2.0ms' and ' $\mathrm{N}-2.0 \mathrm{~ms}$ ' increase at the end of the first injection and decrease after the start of the second injection. The variation extent of excess air ratio for 'P0.5-2.0ms' is more obvious than that for 'P0-2.0ms' and ' $\mathrm{N}-2.0 \mathrm{~ms}$ ' because the interval between the two injections for 'P0.5-2.0ms' is longer, providing enough time for more air to entrain into the fuel spray. At 3.0ms ASOI1, the excess air ratio for 'P0.5-2.0ms' and ' $\mathrm{N}-2.0 \mathrm{~ms}$ ' are close to each other. But the injection amount for ' $\mathrm{N}-2.0 \mathrm{~ms}$ ' is larger than that for 'P0.5$2.0 \mathrm{~ms}$ ', which indicates negative dwell injection can increase the injection amount while achieving a similar atomization effect. It can be found from Figure 8(b) that the gap between the ' $\mathrm{N}-1.0 \mathrm{~ms}$ ' and ' $\mathrm{N}-1.5 \mathrm{~ms}$ ' is larger than that between ' $\mathrm{N}-1.0 \mathrm{~ms}$ ' and ' $\mathrm{N}-1.5 \mathrm{~ms}$ '. ' $\mathrm{N}-2.0 \mathrm{~ms}$ ' has the longest injection duration and hereby the largest injection amount, thus needing more air to get a similar excess air ratio. Considering the hinder effect of the spray of the first injection, the second spray cannot push the head further, then the air in the far area is unable to entrain into the fuel spray.

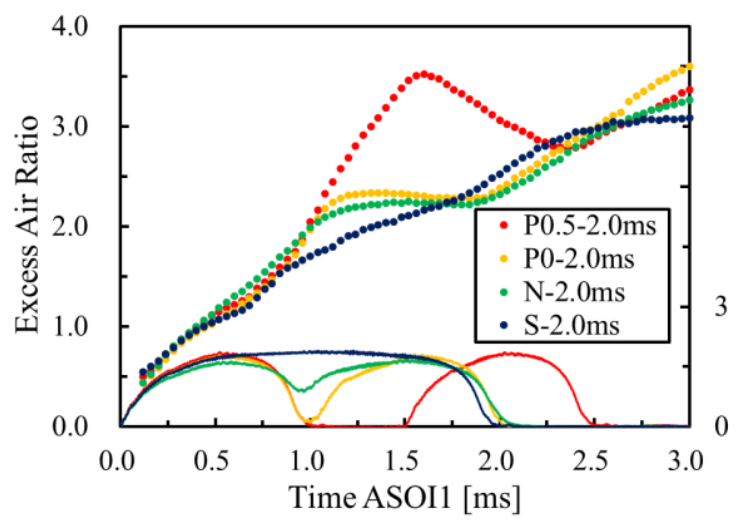

(a) Different Injection Strategies

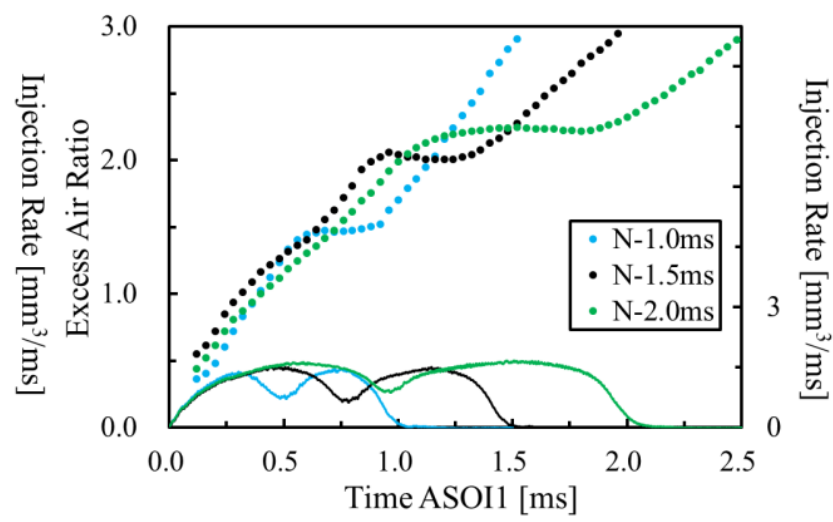

(b) Negative Dwell Injection Strategies with Different Injection Durations

Figure 8. Excess Air Ratio Variation with Time ASOI1

Analysis on the near-field spray behaviors

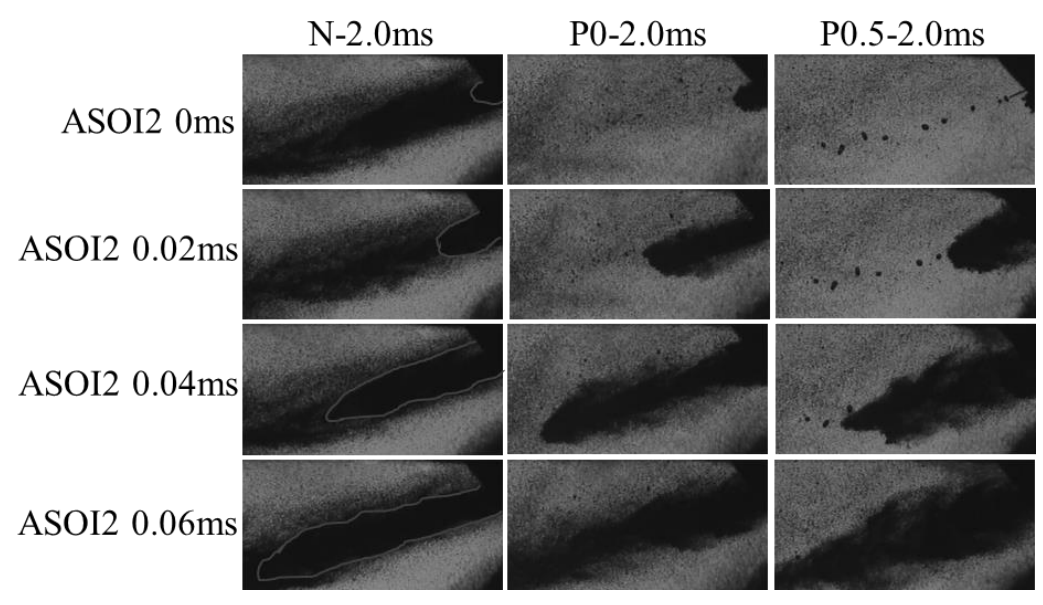

Figure 9. Spray Tip Morphological State for Different Injection Strategies

Figure 9 displays the spray tip at different timings after the second injection. Because the nearfield shooting range is very small, once the spray covers the whole shooting area, it is difficult 
to distinguish the macroscopic difference for different injection strategies. Therefore, the time interval used for analysis is controlled within $0.06 \mathrm{~ms}$ after the second injection. At the start of the second injection, the shooting area is coved with high concentration droplets for ' $\mathrm{N}-2.0 \mathrm{~ms}$ ', low concentration droplets for 'P0-2.0ms' and discrete large droplets for 'P0.5-2.0ms'. Since the second injection of ' $\mathrm{N}-2.0 \mathrm{~ms}$ ' has a larger kinetic energy than other injection strategies, making the fuel droplets be sucked into the moving spray. Therefore, compared with 'P0$2.0 \mathrm{~ms}$ ' and 'P0.5-2.0ms', the edge of the spray for ' $\mathrm{N}-2.0 \mathrm{~ms}$ ' is smoother than that for other injection strategies.

In Figure 4, there exists a red region near nozzle tip after the start of the second injection. Then, we can set a threshold and extract the red region. Combined with the spray penetration stated in Figure 5, the second spray penetration can be obtained. The definition of the second spray penetration ' $S$ ' is specified in Figure 10 and its variation with time is displayed in Figure $11(b)$.

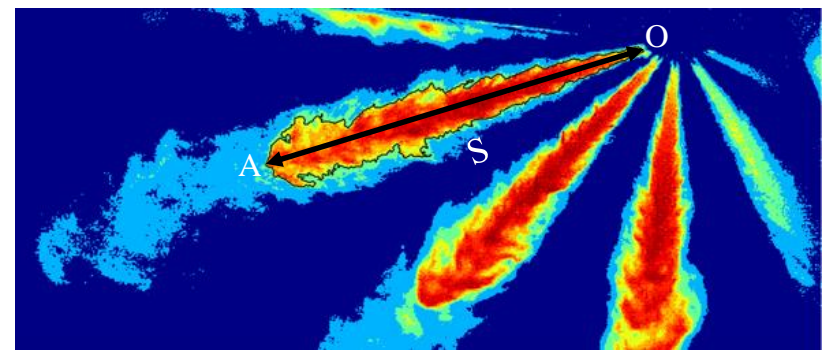

Figure 10. Definition of the Second Spray Penetration

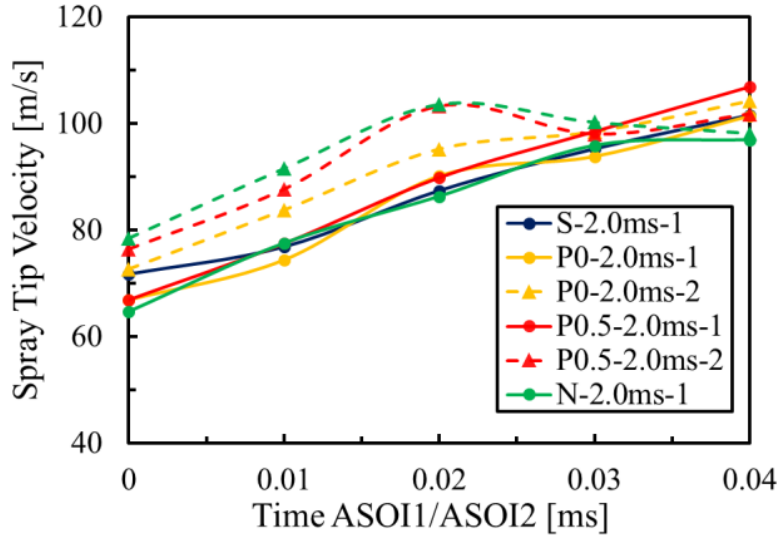

(a) Variation of Spray Tip Velocity with Time

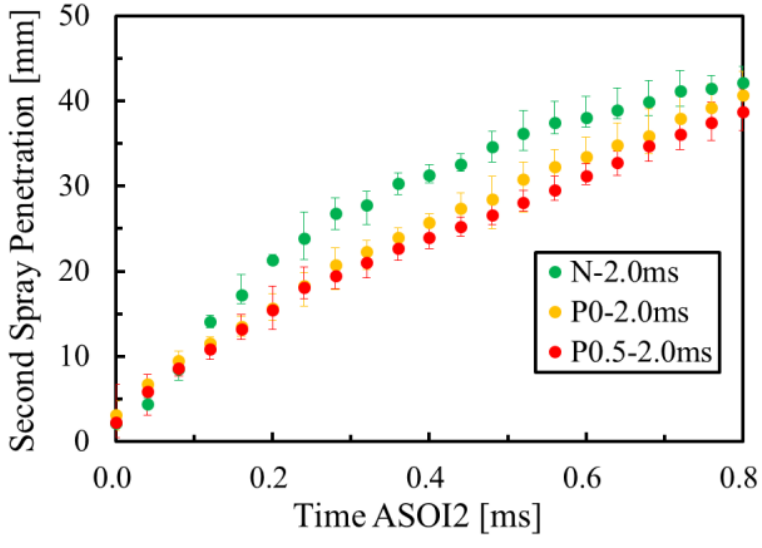

(b) Variation of Second Spray Penetration for Different Injection Strategies

Figure 11. Two Methods of Evaluating Spray Tip Velocity

Meanwhile, the spray tip velocity variation with time obtained from near-field images is shown in Figure 11(a). '1' and '2' represent the spray tip velocity (the average velocity of five times) for the first and second injection, respectively. It can be found from Figure 10 that ' $\mathrm{N}-2.0 \mathrm{~ms}$ ' has larger spray tip velocity than 'P0-2.0ms' and 'P0.5-2.0ms'. At the same time, 'P0.5-2.0ms' has a larger spray tip velocity than 'P0-2.0ms'. Given ' $\mathrm{N}-2.0 \mathrm{~ms}$ ' has a larger injection rate at the start of the second injection, it is easy to understand why it has a larger spray tip velocity. Since the droplet concentration remained by the first injection near nozzle for 'P0-2.0ms' is larger than that for 'P0.5-2.0ms', so the hinder effect caused by droplets will be more evident. Consequently, the spray tip velocity for ' $\mathrm{P} 0-2.0 \mathrm{~ms}$ ' is slightly lower. This phenomenon verifies 
that droplets remained during the first injection will affect the spray development of the second injection.

\section{Conclusions}

Experimental studies are caried out in this paper to find out the spray characteristic difference for different injection strategies with the same injection duration and the difference for negative dwell injection with different injection durations. The conclusions are summarized as below. 1. From far-field results, it can be concluded that most parameters values of negative dwell injection are arranged in the middle of that of the single-injection and positive dwell injection. The high velocity of the second spray for the negative dwell injection provides enough energy for the second spray to catch up with the first spray tip and mix more evenly with each other in a short time. Meanwhile, the negative dwell injection can inject more fuel than the positive dwell injection, but their spray characteristics are close to each other.

2. The near-field results confirm the droplets near nozzle formed by the first injection will hinder the penetration of the second spray. The higher the droplet concentration is, the greater the hinder effect will be.

3. Negative dwell injection strategy can be combined with other injection strategies to optimize the current injection strategies owning to its neutral spray characteristics.

\section{References}

[1] Asghari, M., Mirzapour Al-e-hashem, S. M. J., 2021. International Journal of Production Economics, 231.

[2] Dimitriou, P., Javaid, R., 2020, International Journal of Hydrogen Energy, 45(11), pp. 70987118.

[3] Yousefi, A., Guo, H., Birouk, M., 2020, Applied Energy, 279, pp. 1-14.

[4] Pachiannan, T., Zhong, W., Xuan, T., Li, B., He, Z., Wang, Q., Yu, X., 2019, Renewable Energy, 140, pp. 761-771.

[5] Desantes, J.M., García-Oliver, J.M., García, A., Xuan, T., 2019, International Journal of Engine Research, 20, pp. 606-623

[6] Torregrosa, A. J., Broatch, A., García, A., Mónico, L. F., 2013, Applied Energy, 104, pp. 149-157.

[7] Yang, K., Nishida, K., Ogata, Y., Yamakawa, H., 2018, Fuel, 234, pp. 746-756.

[8] Cheng, X., Chen, L., Yan, F., Hong, G., Yin, Y., Liu, H., Oct. 22-24, 2013, SAE International Congress.

[9] Huang, H., Liu, Q., Yang, R., Zhu, T., Zhao, R., Wang, Y., 2015, Energy Conversion and Management, 106, pp. 748-758.

[10] Shi, H., Tang, Q., An, Y., Raman, V., Johansson, B., 2020, Fuel, 268, pp.1-10. 